\title{
BMJ Open Cohort profile: health effects monitoring programme in Ndilo, Dettah and Yellowknife (YKHEMP)
}

Hing Man Chan (D , ${ }^{1}$ Xue Feng Hu, ${ }^{1}$ Janet S. Cheung, ${ }^{1}$ Rajendra Prasad Parajuli, ${ }^{2}$ Renata Rosol, ${ }^{1}$ Emmanuel Yumvihoze, ${ }^{1}$ Linna Williams, ${ }^{3}$ Asish Mohapatra ${ }^{4}$
To cite: Chan HM, Hu XF, Cheung JS, et al. Cohort profile: health effects monitoring programme in Ndilo, Dettah and Yellowknife (YKHEMP). BMJ Open 2020;10:e038507. doi:10.1136/ bmjopen-2020-038507

- Prepublication history for this paper is available online. To view these files, please visit the journal online (http://dx.doi org/10.1136/bmjopen-2020038507).

Received 12 March 2020 Revised 25 August 2020 Accepted 03 September 2020

Check for updates

(c) Author(s) (or their employer(s)) 2020. Re-use permitted under CC BY-NC. No commercial re-use. See rights and permissions. Published by BMJ.

${ }^{1}$ Biology, University of Ottawa Faculty of Science, Ottawa, Ontario, Canada

${ }^{2}$ Biology, University of Ottawa, Ottawa, Ontario, Canada

${ }^{3}$ Health and Social Services, Government of the Northwest Territories, Yellowknife, Northwest Territories, Canada

${ }^{4}$ Environmental Health Program, Health Canada, Ottawa, Ontario, Canada

Correspondence to

Dr Hing Man Chan;

laurie.chan@uottawa.ca

\section{ABSTRACT}

Purpose The Yellowknife Health Effects Monitoring Programme (YKHEMP) was established to examine the relationship of exposure to arsenic and other chemicals of potential concern such as antimony, cadmium, lead, manganese and vanadium and health outcomes.

Participants A total of 2037 individuals were recruited, including children (age 3-19) and adults (age 20+), residing in Dettah, Ndilo and Yellowknife, in the Northwest Territories, Canada, in two waves in Fall 2017 and Spring 2018. In Yellowknife, there were 891 (675 adults, 216 children), randomly selected participants with a participation rate of $64 \%$. In addition, we also recruited a total of 875 (669 adults, 206 children) volunteer participants. A total of 225 (137 adults, 88 children) of the Yellowknives Dene First Nation (YKDFN), and 46 (33 adults, 13 children) of the North Slave Métis Alliance participated in the study. Each participant answered a lifestyle questionnaire as well as provided toenail clippings and urine for contaminant testing and saliva samples for testing of genetic polymorphisms associated with arsenic metabolism. Participants also provided consent to have their medical records reviewed by the research team for the past 5 years to allow for the investigation between exposure and health outcomes.

Findings to date The adult YKHEMP participants had lower urinary total arsenic but the children had higher inorganic arsenic than the general Canadian population. There was no difference in urinary total arsenic concentrations between adults and children, however, urinary inorganic arsenic concentrations were generally higher in children than in adults in all four YKHEMP sampling groups. The adult YKDFN participants had lower urinary total arsenic and inorganic arsenic concentrations compared with the random selected and volunteer participants.

Future plans YKHEMP is designed as a prospective cohort study; the children participants will be re-examined in 2022 and both adult and children participants in 2027.

\section{INTRODUCTION}

Giant Mine was a gold mine located within the boundary of the city of Yellowknife, where it operated from 1948 to 2004 . The site reverted to the Crown when owner Royal Oaks Mine went into receivership in 1999. Gold was extracted from arsenopyrite ores through

\section{Strengths and limitations of this study}

Multiple validations were designed to account for potential inaccuracy in exposure characterisation and recalling bias in the questionnaire interview.

- Community meetings were organised with each population to review study protocols and seek public input.

- Does not address the potential long-term effects of legacy arsenic exposure of the populations in Yellowknife when the Giant Mine was still in operation.

- Urine is a good medium to measure arsenic exposure; however, it may not be the optimal one for the other chemicals of potential concern, for example, lead.

a roasting process that generated arsenic trioxide as a toxic byproduct. As a result, there are currently 237000 tonnes of arsenic trioxide dust present at the site, contained in 15 underground chambers, and 4 large tailings ponds. Between 1949 and 1953, an estimated 16500 pounds or about $7500 \mathrm{~kg}$ of arsenic trioxide dust was released into the environment every day without any filtration. ${ }^{1}$ Following reports of arsenic poisoning in the 1950s, a baghouse filtration system was installed in 1958 to filter and store the arsenic trioxide in underground chambers. ${ }^{1}$

At present, the mine is considered one of the most contaminated sites in Canada. ${ }^{2}$ Although Giant Mine is no longer in operation, there are concerns of chemical contamination originating from the site via surface runoff and groundwater migration or from historical aerial deposition. ${ }^{3}$ The list of chemicals of potential concern (COPCs) includes arsenic, antimony, cadmium, lead, manganese and vanadium. Arsenic exposure is of particular concern and arsenic is highly toxic in its inorganic form. Long-term exposure to arsenic from drinking water and food are associated with cancer, skin lesions, 
cardiovascular disease and diabetes. ${ }^{4-9}$ Chronic exposure to other COPCs were associated with various adverse health outcomes. ${ }^{10}$ To address concerns about arsenic and other COPCs, the Giant Mine Remediation Project was established and approved by the Mackenzie Valley Environmental Impact Review Board. The Giant Mine Remediation Project's primary goal is to protect human health and the environment. To do so, the Project is focused on the long-term containment and management of the stored underground arsenic trioxide waste, demolition and removal of on-site buildings, water management and treatment, and the remediation of all surface areas including the tailings ponds at the Giant Mine site. As required by the review board, the Project is subject to 26 measures aimed at preventing significant adverse impacts on the environment and public health and mitigating public concern.

This research programme titled 'Health Effects Monitoring Programme in Ndilo, Dettah and Yellowknife (YKHEMP)' was developed to make sure the remediation activities that take place at Giant Mine will not have a negative impact on people's health. The project objective will be achieved by investigating the exposure and impact of the COPCs, particularly arsenic, on the Ndilo, Dettah and Yellowknife population. The YKHEMP will be a longterm programme that will monitor the level of COPCs within the human population as the remediation at the Giant Mine progresses.

The overall objective of YKHEMP is to implement a broad health effects biomonitoring programme for the population of Yellowknife, Ndilo and Dettah, focusing on arsenic and other COPCs such as antimony, cadmium, lead, manganese and vanadium. It will provide a comprehensive overview of the levels of contaminants currently present in the human population. The specific project objectives are as follows:

A. Compare body-burden of COPCs in YKHEMP participants to those reported in national biomonitoring study, the Canadian Health Measures Survey (CHMS).

B. Investigate the associations between COPC concentrations, particularly arsenic and the observed/reported health outcomes in YKHEMP participants.

C. Explore results sharing with other related studies to understand sources of contaminant exposure and their relationships with health outcomes in Yellowknife.

D. Establish a detailed protocol, including a set of benchmarks for the future ongoing monitoring programme.

\section{COHORT DESCRIPTION}

\section{Study population}

YKHEMP is a prospective cohort study, and it comprises four groups of participants; (1) randomly selected Yellowknife participants, (2) Yellowknives Dene First Nation (YKDFN), (3) North Slave Métis Alliance (NSMA) members and (4) volunteer Yellowknife participants. Yellowknife has a population of roughly 21183 residents including 1540 Yellowknives Dene, in 10 districts. Participant recruitment and biomonitoring were conducted from September 2017 to December 2017 (wave 1) and from April 2018 to June 2018 (wave 2) for the baseline survey. The two-wave approach was designed to account for any potential seasonal effect on levels of COPC in biological samples and risk factors for exposure such as water recreation activities, fishing, children playing outdoors with bare foot.

For the Yellowknife general population, a two-stage stratified systematic sampling approach was used to yield a representative sample of residents from 3 to 79 years, who have lived in Yellowknife for at least 1 year, excluding members of the YKDFN and NSMA. The population in Yellowknife was estimated to be approximately 20000 . For a confidence level of $5 \%$, the required sample size was 1000 . The sample size increased to 2000 after accounting for a non-response rate of $50 \%$, and to 2500 after accounting for out-of-scope rate of $20 \%$ (dwellers have been residing in Yellowknife for less than 1 year), and to 2800 after accounting for an occupancy rate of $90 \%$. On average, 1.5 persons (assuming $50 \%$ of the households have children) were expected to be selected using the number of households from the 2011 Census. Thus, 1900 households were the target sample. A list of the dwellings that contained 6886 residential addresses was provided by the City of Yellowknife municipality. A sample of 1900 addresses were selected in random and then divided into two waves of collection, September 2017 and April 2018. From each selected household, up to one adult (18+) and one child (3-17) was randomly selected based on whose birth date was next. Population aged 6 and above were invited to participate during wave 1 , and the population aged 3 and above were included in wave 2 .

For YKDFN, a mixed sampling approach was adopted, as suggested by the Yellowknives Dene leadership. All YKDFN members were invited to participate on a voluntary basis. Additional members were contacted and invited to participate if a specific demographic or household characteristic was lacking to better represent the population. For the NSMA, all members were invited to participate as recommended by the NSMA leadership. In responding to the request of the Yellowknife residents during the consultation period, the study also welcomed any resident who volunteered to participate, thus forming the fourth group.

A total of 2037 individuals participated in the baseline survey, which included 891 randomly selected general population participants with a participation rate of $64 \%$, 875 volunteer participants from the general population, a total of 225 YKDFN and 46 NSMA members. For the randomly selected participants, survey weights were generated to account for the sampling probability and non-response rate. A set of 500 bootstrap weights was also generated to account for the sampling error. Details of the demographic and socioeconomic characteristics for the four participation groups are shown in table 1. 
Table 1 Sociodemographic characteristics by participant group in the Yellowknife Health Effects Monitoring programme

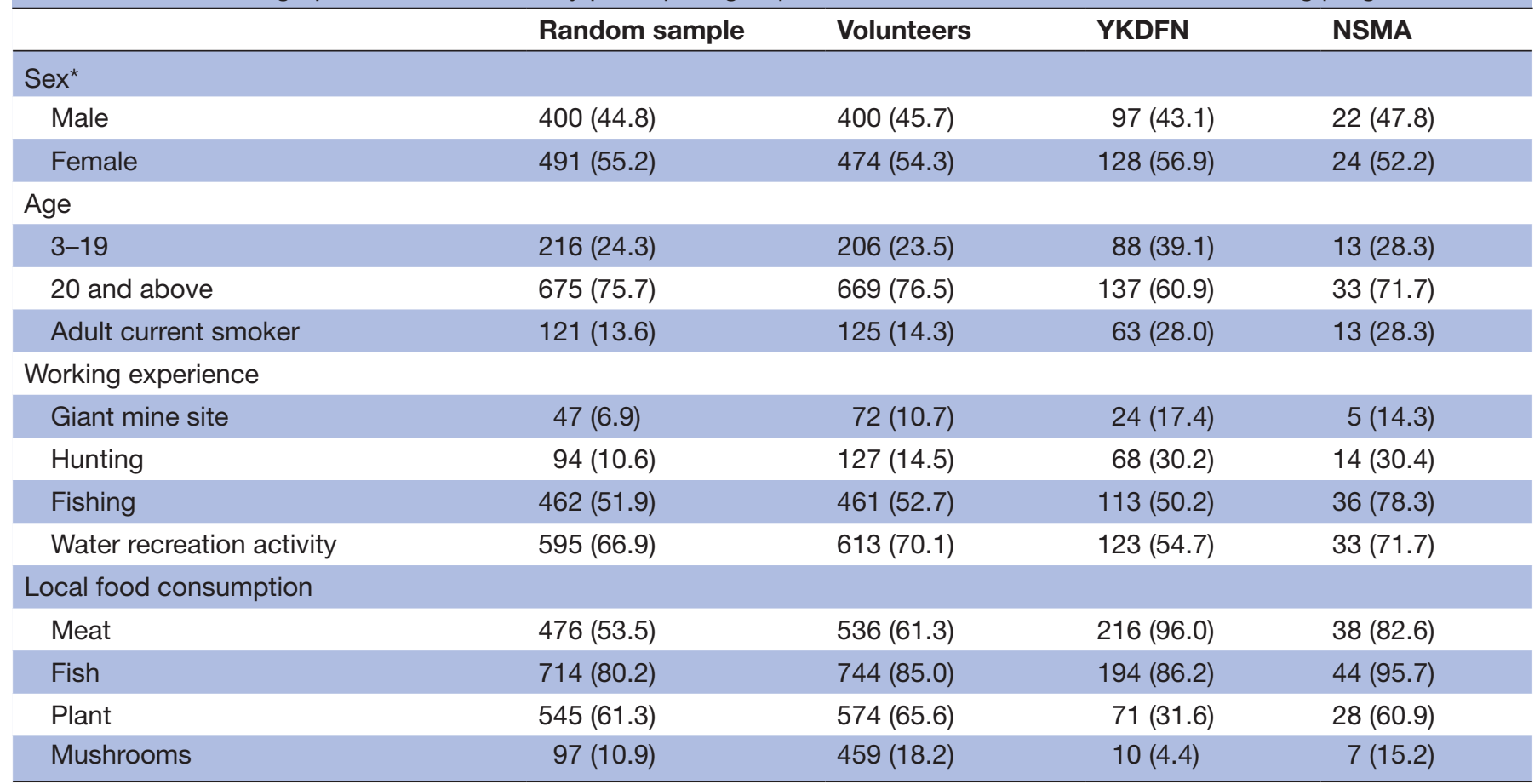

The bracketed numbers are the percentage of all participants within the group.

*One volunteer participant self-identified sex as 'other'.

NSMA, North Slave Métis Alliance; YKDFN, Yellowknives Dene First Nation.

YKHEMP is designed as a prospective cohort study that will last for at least 10 years (figure 1 ).

Phase 2, 2022-2023

The children who participated in the baseline survey (2017-2018) will be contacted again. A random selection will be conducted to make up for the attrition of participants over the 5-year period, in case that some of these children will not live in Yellowknife at the time of resampling.

Phase 3, 2027-2028

All participants (children and adults) from the baseline survey (2017-2018) and the children from phase 2 (2022-2023) will be contacted. In addition, another sample of adults and children will be selected in 20272028 to make up for the attrition of participants over this 10 -year period. This sample will be designed later with the updated values for the population size of Yellowknife and updated requirements for the project.

The retrospective phase of YKHEMP collected the medical history of all participants for up to 5 years. The baseline survey of YKHEMP includes three main components: questionnaire interview, physical examination (YKDFN only), laboratory chemical measurements and genotyping (table 2).

All participants were invited to complete a Lifestyle Questionnaire. The lifestyle questionnaire contained two components: general information and exposure

Yellowknife Health Effects Monitoring Program

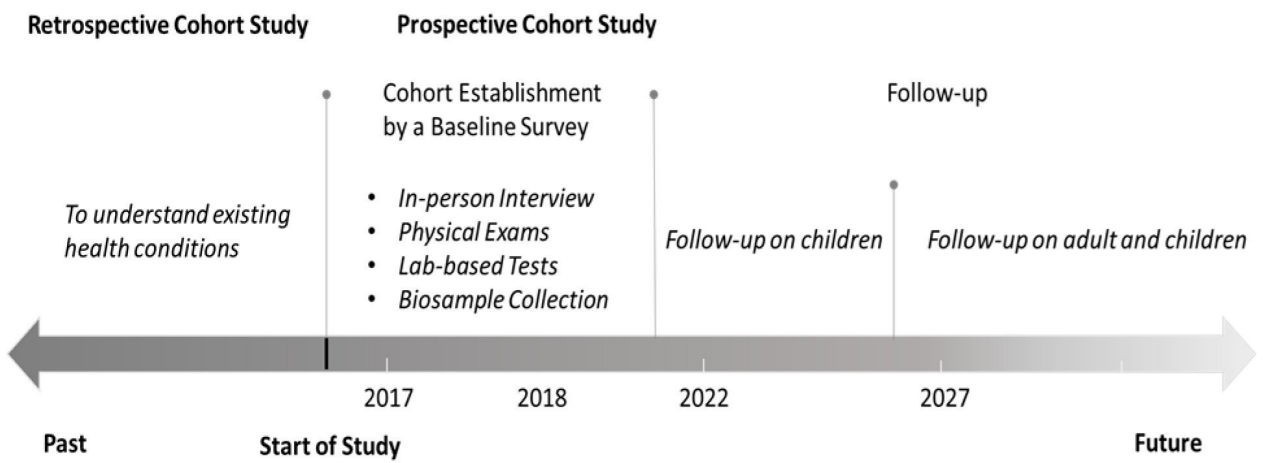

Figure 1 Study design for the YKHEMP. YKHEMP, Yellowknife Health Effects Monitoring Programme. 
Table 2 Summary of measurements at baseline in the Yellowknife Health Effects Monitoring programme

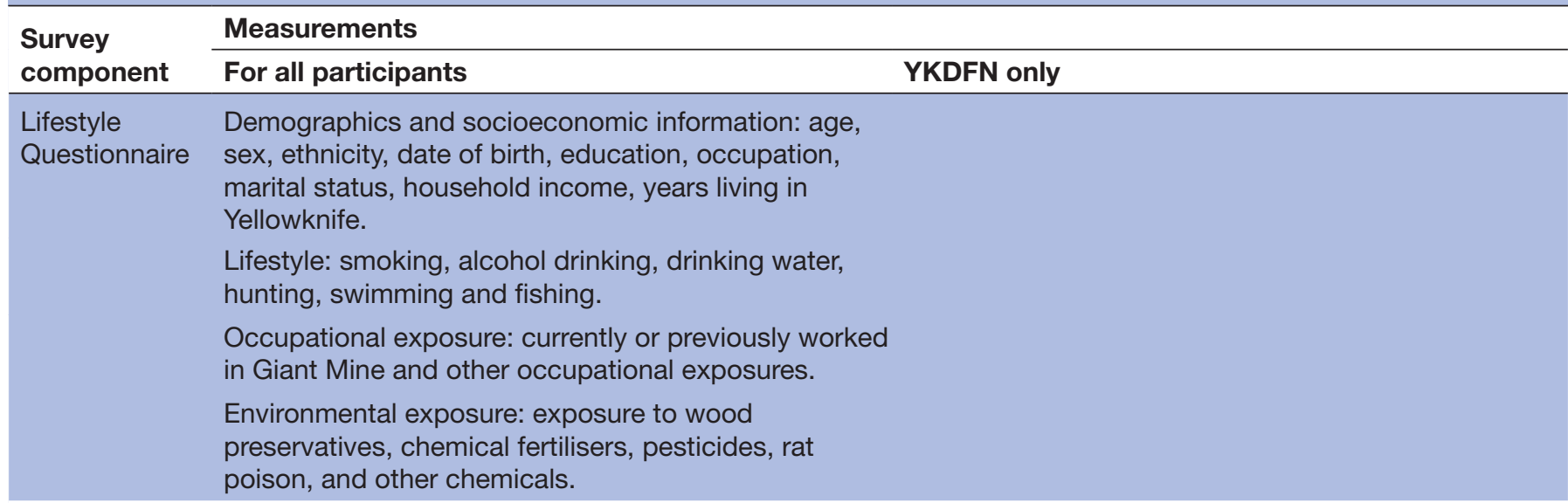

Food frequency Consumption of locally harvested fish, locally grown

Questionnaire vegetables/herbs and locally collected berries, mushrooms, wild fungus and other wild plants; consumption of fish, shellfish, rice and rice product from store.

Consumption of different types of locally harvested meat, local lake fish, locally grown vegetables and herbs and locally collected berries, mushrooms, tea, birch sap and spruce gum.

\begin{tabular}{|c|c|c|}
\hline $\begin{array}{l}\text { Physical } \\
\text { examination }\end{array}$ & & $\begin{array}{l}\text { Anthropometric measures: weight, height and blood } \\
\text { pressure. }\end{array}$ \\
\hline $\begin{array}{l}\text { Medical } \\
\text { Questionnaire }\end{array}$ & & $\begin{array}{l}\text { Medication and symptoms: dermatological, } \\
\text { respiratory, cardiovascular, haematological, hepatic, } \\
\text { neurological, cancer, other. }\end{array}$ \\
\hline \multirow[t]{2}{*}{$\begin{array}{l}\text { Laboratory } \\
\text { chemical } \\
\text { measurements }\end{array}$} & $\begin{array}{l}\text { Urinary concentrations of total arsenic, different } \\
\text { components of inorganic arsenic, vanadium, } \\
\text { manganese, cadmium, antimony, and lead, CC16 and } \\
\text { KIM-1 (for children only). }\end{array}$ & \\
\hline & $\begin{array}{l}\text { Toenail concentrations of arsenic, vanadium, } \\
\text { manganese, cadmium, antimony and lead. }\end{array}$ & \\
\hline $\begin{array}{l}\text { Medical } \\
\text { records }\end{array}$ & $\begin{array}{l}\text { Diseases certified by ICD- } 9 \text { codes and medical } \\
\text { conditions identified from free text in the medical } \\
\text { record: cancer including skin cancer and melanoma, } \\
\text { heart disease, diabetes, various symptoms related to } \\
\text { arsenic exposure. }\end{array}$ & \\
\hline
\end{tabular}

ICD-9, International Classification of Diseases, Revision 9; YKDFN, Yellowknives Dene First Nation.

history (eg, lifestyle, diet, water source, occupational history). Participants were also asked to complete a short Food Frequency Questionnaire (FFQ) on the types and amounts of local harvested fish consumed. Information about serving sizes was collected using food models. The FFQ also included other fish, shellfish, rice and rice products purchased from the market; locally grown vegetables/herbs and locally collected berries, mushrooms, wild fungus and other wild plants. The FFQ for the YKDFN included additional components including the types and amounts of local traditional foods including wild animals, wild birds, wild berries, wild plants for tea, other edible plants: greens, onions, rhubarb, spruce gum, birch sap and mushrooms consumed, as suggested by the YKDFN leadership. All participants were also asked to complete a medical questionnaire and invited to undergo a brief medical exam that included taking a person's height, weight and blood pressure. The medical history included diagnosed diseases, for example, hypertension, diabetes, cancer and common clinical symptoms associated with arsenic exposure. ${ }^{6}$ Parents completed the questionnaires on their child's behalf for any children from 3 to 12 years of age. However, starting from age 13, the youth was able to answer the questionnaire for themselves. Diseases were 
extracted according to International Classification of Diseases, Revision 9 and clinical symptoms were extracted through keyword searching in the participants' medical records from the Wolf EMR electronic medical record system, which was launched in 2014. Medical records start at birth of each child but they are not linked to the parents' records. The list of symptoms and medical conditions included in the medical history questionnaire are presented in online supplemental material 1 and the search terms for the medical records are presented in online supplemental material 2.

For children (ages 6-17), we measured CC16 and KIM-1 in urine as two candidate biomarkers of effect for arsenic on the lung and the kidney, respectively. CC16, a secretory protein in the lung and KIM-1, a molecule upregulated in the kidneys. ${ }^{11-14}$ Urine samples were analysed for CC16 and KIM-1 using ELISA as described elsewhere. ${ }^{12} 13$ The primary antibodies used were Monoclonal Antibodies AY1E6 and ARD5 for CC16 and KIM-1, respectively.

Urine, toenail and saliva samples were collected, and COPCs were analysed for participants. Sample kits were distributed to all participants by trained research assistants to collect urine, toenail clippings and saliva, at their own time. Toilet hat was provided for the collection of urine for young children (3-6years). Participants were instructed to abstain from eating seafood 3 days before urine sampling and to provide the first-morning urine void. Samples were kept at the local research office under appropriate storage conditions: at room temperature for saliva and toenails, and in the refrigerator at $4^{\circ} \mathrm{C}$ for urine, and until shipped to the University of Ottawa (urine and toenail) or Génome Quebec (saliva) for analysis within 30 days. All chemical analyses were performed at the Laboratory for the Analysis of Natural and Synthetic Environmental Toxicants at the University of Ottawa. Concentration of arsenic and COPCs in the urine and digested toenail were analysed using inductively coupled plasma mass spectrometry (ICP-MS) (7700x ICP-MS, Agilent Technologies, Japan). For quality control, certified reference materials, as well as in-house and external quality controls were used (eg, field blanks and spiked samples). Details of the sample processing and chemical analysis procedures can be found elsewhere (http:// www.ykhemp.ca/reports.php). To ensure laboratory analysis quality, $2.5 \%$ of the urine samples were randomly selected and sent to Institut National de Santé Publique du Québec. There was a strong correlation between the two sets of results, and there was no statistical difference in both total and inorganic arsenic results. The detection limit in the urine samples was $0.012 \mathrm{ug} / \mathrm{L}$ for total arsenic, $0.005 \mathrm{ug} / \mathrm{L}$ for the arsenic species, $0.007 \mathrm{ug} / \mathrm{L}$ for cadmium and $0.02 \mathrm{ug} / \mathrm{L}$ for lead. The detection limit in the toenail samples was $0.05 \mathrm{ug} / \mathrm{kg}$ for total arsenic. The detection limits of CHMS were $0.5 \mathrm{ug} / \mathrm{L}$ for total arsenic, $0.8 \mathrm{ug} / \mathrm{L}$ for the arsenic species and $0.1 \mathrm{ug} / \mathrm{L}$ for cadmium and lead, respectively. ${ }^{15}$

Genetic polymorphisms may occur as sequences or single nucleotides. The latter is referred to as single nucleotide polymorphism (SNP). Several SNPs have been identified to be associated with arsenic, most notably the metabolism of arsenic. ${ }^{16-25}$ Based on previous evidence, 72 SNPs were selected that were hypothesised to underlie interindividual differences in arsenic metabolism including SNPs in genes of the following pathways and classes: sheath interacting, nucleotide excision repair, organic anion transporter, reduction activity in arsenic metabolism, DNA repair, efflux carrier, transporter (ZIP family metal transporter), one-carbon metabolism and folate metabolism pathway. In this study, buccal swabs were collected from participants using a DNA Genotek buccal swab kit (OCR-100) and sent to Genome Quebec where DNA was isolated from buccal swab with the QIA symphony instrument along with the DSP Midi kit (cat\# 937255, QIAGEN) according to the manufacturer's protocol, and genotyped using the Sequenom iPLEX Gold platform. ${ }^{26}$

\section{Immediate follow-up of participants with potential high exposure}

Participants with urine sample of at least one of the COPCs exceeding the reference values (the 95th percentile of the CHMS) will be followed up and have urine samples retested to confirm the higher exposure as well as given advice on ways to lower their exposure. Participants with persistently elevated levels will be followed up every 6 months. As no reference values are available for toenail arsenic, the Health Effects Monitoring Programme Advisory Committee (HEMPAC) decided to use the 80th percentile for children and 95th percentile for adults as screening levels for arsenic in toenails to identify participants with an elevated level of exposure for follow-up. Participants who had urinary lead concentrations exceed the reference values were asked to have their blood lead concentrations measured to confirm the lead exposure.

\section{Patient and public involvement}

There is no patient involved in this study. Our study adopts an integrated knowledge approach to involve the public. A HEMPAC was created as a mechanism for member stakeholders to contribute to the development and implementation of the study. HEMPAC meets once a month and consists of the following representatives: Crown-Indigenous Relations and Northern Affairs Canada, the Government of the Northwest Territories Department of Environment and Natural Resources, the Government of the Northwest Territories Department of Health and Social Services, Health Canada, City of Yellowknife, YKDFN, NSMA, Giant Mine Oversight Board and the University of Ottawa.

The HEMPAC will continue the collaboration, consultation and coordination on matters arising from the YKHEMP, including ongoing data analyses, management of data files and requests from researchers and students for access to data, the approval process for publications and conference presentations, reports, funding opportunities, knowledge translation and intervention strategies. 
A detailed communication plan has been developed to facilitate public engagement. Progress of the study and results are communicated through public meetings, news channels, social media and web site www.ykhemp.ca.

\section{Statistical analysis}

Geometric mean and the corresponding 95\% CI for urinary and toenail COPC concentrations are reported. Urinary inorganic arsenic concentration was calculated as the total concentration of arsenite As(III), arsenate As $(\mathrm{V})$, monomethylarsonic acid and dimethylarsinic acid. Values below the limit of detection (LOD) were replaced with half the LOD. Sample weights and 500 bootstrap weights were used to adjust for sampling design, generate population-representative statistics, and to produce appropriate variance estimation for both the YKHMEP random sample and the CHMS. Combined data on urine total arsenic, cadmium and lead collected in CHMS cycles 1 (2007-2009) and 2 (2009-2011) and the combined data for urine inorganic arsenic collected from CHMS cycles 2 (2009-2011), 3 (2012-2013) and 4 (2014-2015) were used as references. ${ }^{1527}$ The data were merged with the appropriate combined weights file for the specific combination of cycles being combined and taking into account differences in age. As CHMS did not measure arsenic in the toenail, there is no comparable data for reference levels as in the case for metals in urine samples. All analyses were performed using Stata SE (V.14). A two-sample t-test was performed to compare the urinary COPC concentrations between YKHEMP populations and the Canadian general population concentrations, as reported by the CHMS. Sampling weights were used for comparisons between YKHEMP random sample and the CHMS. The details of laboratory procedures of $\mathrm{CHMS}^{15}$ and
YKHEMP can be find elsewhere (http://www.ykhemp. ca/reports.php).

\section{Findings to date}

Among the 2037 YKEHMP participants, 1966 participants have urinary COPC measurements, and 1872 have toenail COPC measurements. Urinary total arsenic, inorganic arsenic, cadmium and lead concentrations are presented in table 3. In general, the urinary total arsenic concentration was lower in the YKHEMP participants (especially in YKDFN and NSMA children), compared with the CHMS. However, for urinary inorganic arsenic, children participants from the Yellowknife randomised sample group, the volunteer group and the YKDFN had higher urinary concentrations than the adults within the group, as well as CHMS results for the same age group (especially age 6-11, table 4). YKHEMP participants (both children and adults) had lower urinary cadmium concentrations, compared with the CHMS participants. Within YKHEMP participants, children had lower urinary cadmium concentrations compared with adults. The urinary lead concentration of YKHEMP participants was comparable to CHMS participants. In general, YKHEMP children participants had lower urinary concentrations of total arsenic, cadmium and lead, compared with adults; however, children were found to have higher toenail concentrations of such COPC (table 5).

It is important to note that, in addition to contamination from historical gold mining activity, arsenic also occurs naturally in the Yellowknife area because of the local geological formations. The YKHEMP study currently cannot distinguish arsenic exposures from natural sources, the Giant mine or dietary sources. Several ongoing analyses are being conducted to gain a

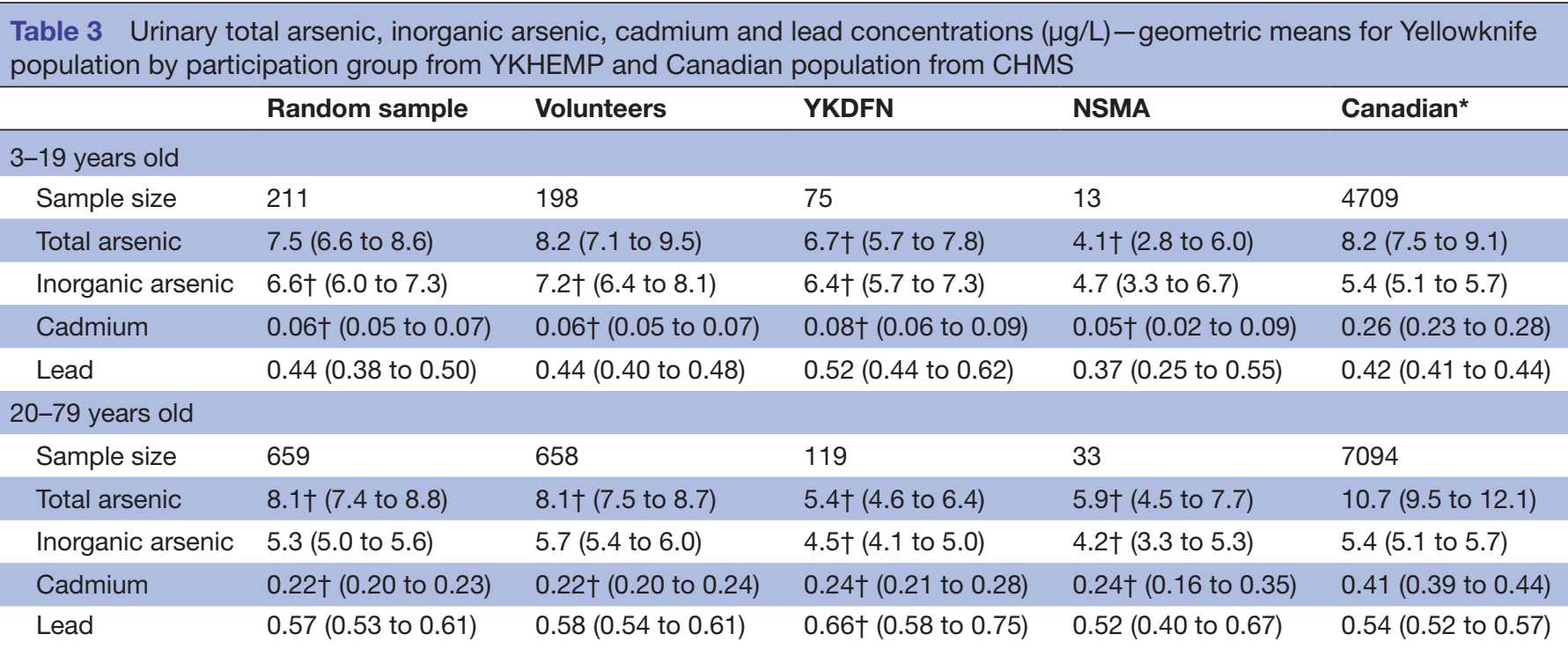

Values presented in the parentheses are the $95 \% \mathrm{Cl}$.

*Presented numbers are the sample size for total arsenic, cadmium and lead, the sample size for inorganic arsenic differ from these. †Significantly different from CHMS.

CHMS, Canadian Health Measures Survey; NSMA, North Slave Métis Alliance; YKDFN, Yellowknives Dene First Nation; YKHEMP, Yellowknife Health Effects Monitoring Program. 
Table 4 Urinary total arsenic and inorganic arsenic concentrations $(\mu \mathrm{g} / \mathrm{L})$ - geometric means (GM) for randomly selected samples from YKHEMP and Canadian population aged 3-79 from CHMS cycle 1 and 2

\begin{tabular}{|c|c|c|c|c|c|c|c|}
\hline \multirow[b]{3}{*}{ Age group } & \multirow[b]{3}{*}{$\mathrm{n}$} & \multicolumn{3}{|c|}{ YHKEMP random sample } & \multicolumn{3}{|l|}{ CHMS } \\
\hline & & & Total arsenic & Inorganic arsenic & & Total arsenic & Inorganic arsenic \\
\hline & & Weighted N & GM $(95 \% \mathrm{Cl})$ & GM $(95 \% \mathrm{Cl})$ & Weighted N & GM $(95 \% \mathrm{Cl})$ & GM $(95 \% \mathrm{Cl})$ \\
\hline $6-11$ & 91 & 1579 & 9.0 (7.0 to 11.6$)$ & $7.3(6.2 \text { to } 8.8)^{*}$ & 2122370 & 8.1 (7.5 to 8.9$)$ & 5.5 (5.1 to 5.8$)$ \\
\hline $12-19$ & 81 & 1529 & $6.4(5.2 \text { to } 7.8)^{\star}$ & $6.0(5.3$ to 6.9$)$ & 3287580 & $9.1(8.0$ to 10.4$)$ & 5.5 (5.0 to 5.9$)$ \\
\hline $40-59$ & 292 & 5538 & $7.9(7.0 \text { to } 9.0)^{*}$ & 4.9 (4.5 to 5.4$)$ & 9827356 & 10.7 (9.2 to 12.3$)$ & 5.1 (4.7 to 5.6$)$ \\
\hline $60-79$ & 107 & 1841 & $7.4(5.9 \text { to } 9.2)^{\star}$ & 4.4 (3.8 to 5.1$)$ & 5116239 & $11.2(9.4$ to 13.4$)$ & 5.3 (4.9 to 5.8$)$ \\
\hline
\end{tabular}

Sample size for CHMS suppressed due to Statistics Canada requirement. Values presented in the parentheses are the $95 \% \mathrm{Cl}$. *Significantly different from CHMS.

CHMS, Canadian Health Measures Survey; YHKEMP, Yellowknife Health Effects Monitoring Program.

better understanding of the sources of arsenic exposure in Yellowknife and its potential health impacts. Arsenic species will be measured in different layers of the toenail. This will help to understand the proportion of arsenic exposure from dietary sources and toenail contamination from external contact (surface metal/contaminant adsorption).

YKHEMP provides a unique opportunity to understand the potential long-term health impacts as the Giant Mine Remediation Project progresses, which may also apply to remediation processes at other mining sites worldwide. YKHEMP has several strengths. Both urine and toenail samples were collected. Metal concentrations in urine and toenail provide an estimate of arsenic and other COPC exposure in different time periods and forms. ${ }^{28-31}$ Indigenous people (YKDFN and NSMA) who were more vulnerable to environmental contamination were also included in the YKHEMP. YKDFN live closer to the Giant Mine area compared with other YKHEMP participants. The higher rates of consumption of locally harvested food also make YKDFN and NSMA more likely to have a higher exposure to arsenic and other COPCs from dietary sources. The comparison of their arsenic exposure and health conditions to other YKHEMP participants, as well as to the Canadian population, may provide additional information on arsenic's health effect. A separate medical history questionnaire was designed for YKDFN as well. The information collected by this questionnaire will be compared with the medical file. Community involvement is another strength of the YKHEMP. YKHEMP welcomed volunteers to join the study. The number of volunteers was similar to the random sample. By comparing the arsenic exposure levels in the randomly selected sample and the volunteers, we will be able to see if any individual or group with high exposure might be ignored by systematic sampling. In addition, it will help in identifying possible participation bias. In this study, buccal swabs were collected from participants. Analysis of polymorphisms will provide indications on how the genetic makeup of the study participants may affect the metabolism and kinetics of arsenic.

One weakness of the study is that it does not address the potential long-term effects of legacy arsenic exposure of the populations in Yellowknife when the Giant Mine was still in operation. The baseline measurement of urine and toenail only reflect arsenic exposure of the participants in recent days or months before the sample

Table 5 Toenail total arsenic, cadmium and lead concentrations $(\mu \mathrm{g} / \mathrm{g})$ - geometric means for the Yellowknife population by participation group from YKHEMP

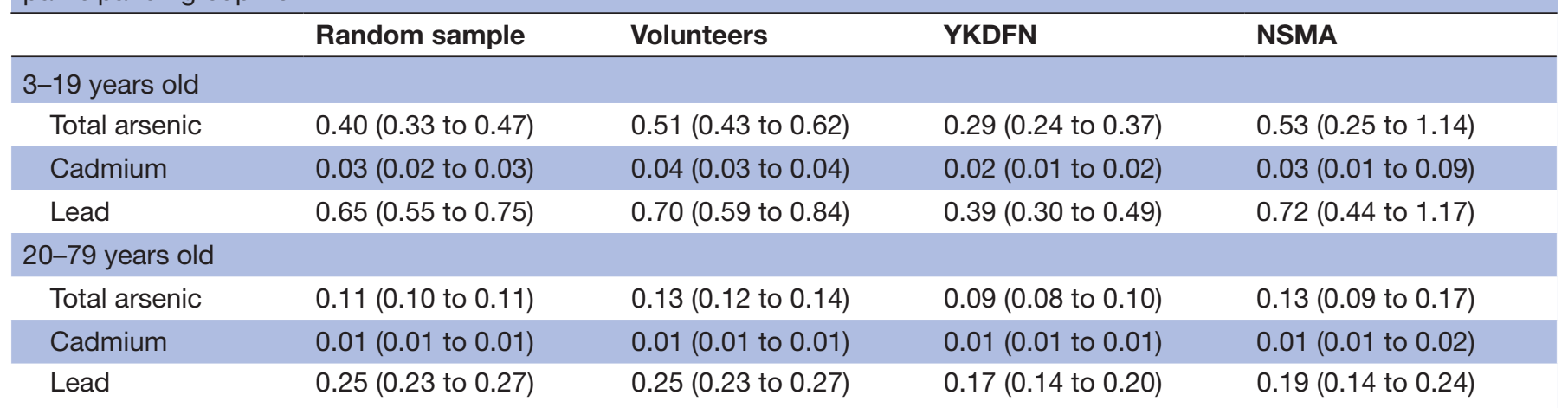

Values presented in the parentheses are the $95 \% \mathrm{Cl}$.

NSMA, North Slave Métis Alliance; YKHEMP, Yellowknife Health Effects Monitoring Program. 
collection period. Therefore, while the YKHEMP baseline and subsequent data will provide essential information regarding the potential health impact during and after the Giant Mine remediation process in the future, it will be limited in examining the association between legacy arsenic exposure and its long-term health impact. Urine is a good medium to measure arsenic exposure; however, it may not be the optimal one for the other COPCs, for example, lead. Finally, this study only aims to address health risks associated with chemical exposures and does not capture other indirect health risks such as those related to changes in their traditional diet and lifestyle. It also only reports current body burden and has not accounted for behavioural changes that people may have taken to protect themselves from arsenic in the environment, for example, not picking berries near the mine site, travelling further from their community to fish and hunt, and reduce their local fish and meat consumption.

\section{Collaboration}

The HEMPAC has full governance of and access to the data, however, the University of Ottawa maintains the database. Investigators interested in learning more about the Project and how to obtain YKHEMP data can contact ykhemp@uottawa.ca.

\section{Twitter Rajendra Prasad Parajuli @parajulirp}

Acknowledgements We would like to thank those who have been involved in the Health Effects Monitoring Program. The Health Effects Monitoring Program Advisory Committee, the research assistants and research nurses involved in data collection, and technicians involved in laboratory analyses. We would also like to acknowledge those involved in questionnaire programming, website design, translation of survey materials, and staff from Statistics Canada in facilitating survey sampling. The analysis presented in this report (CHMS part) was conducted at the COOL RDC, which is part of the Canadian Research Data Centre Network (CRDCN). The services and activities provided by the COOL RDC were made possible by the financial or in-kind support of the SSHRC, the CIHR, the CFI, Statistics Canada, Carleton University, University of Ottawa, and the Université du Québec en Outaouais. We would also like to thank the members of the Advisory Committee and Subramanian Karthikeyan from Health Canada for providing constructive comments to the manuscript.

Contributors HMC was responsible for the funding acquisition, conception and design of the study; data acquisition and interpretation; and drafting and revising the manuscript. XFH, JC and RPP were responsible for data acquisition, analysis and interpretation; and drafting and revising the manuscript. RR and EY were responsible for data acquisition and interpretation; and revising the manuscript. LW and $\mathrm{AM}$ were responsible for conception and design of the study, data acquisition and interpretation; and revising the manuscript. All contributors agreed to be accountable for all aspects of the work in ensuring that questions related to the accuracy or integrity of any part of the work are appropriately investigated and resolved.

Funding Funding was provided by the Crown-Indigenous Relations and Northern Affairs Canada. Hing Man Chan is a holder of a Canada Research Chair funded the Canada Research Chair Program. Award/Grant number is not applicable for both funding sources.

Competing interests None declared.

Patient and public involvement Patients and/or the public were involved in the design, or conduct, or reporting, or dissemination plans of this research. Refer to the Methods section for further details.

Patient consent for publication Not required.

Ethics approval The study is approved by the Health Sciences and Sciences Research Ethics Board of the University of Ottawa (http://research.uottawa.ca/ ethics/reb) and the Aurora College Research Ethics Committee. In addition, the study has been granted a Scientific Research License from the Aurora Research Institute in Northwest Territories. Individual participation in the project was voluntary and based on informed written consent following an oral and written explanation of each project component.

Provenance and peer review Not commissioned; externally peer reviewed.

Data availability statement Data are available on reasonable request. Investigators interested in learning more about the Project and how to obtain YKHEMP data can contact ykhemp@uottawa.ca.

Open access This is an open access article distributed in accordance with the Creative Commons Attribution Non Commercial (CC BY-NC 4.0) license, which permits others to distribute, remix, adapt, build upon this work non-commercially, and license their derivative works on different terms, provided the original work is properly cited, appropriate credit is given, any changes made indicated, and the use is non-commercial. See: http://creativecommons.org/licenses/by-nc/4.0/.

ORCID iD

Hing Man Chan http://orcid.org/0000-0003-4351-7483

\section{REFERENCES}

1 Sandlos J, Keeling A. Giant mine: historical summary, 2012 Available: http://reviewboard.ca/upload/project_document/EA0809001_Giant_Mine_History_Summary.PDF [Accessed 19 Aug 2019].

2 Officer of the Auditor General Canada. Chapter 3 - Federal contaminated sites and their impacts. In: 2012 spring report of the commissioner of the environment and sustainable development, 2012. http://www.oag-bvg.gc.ca/internet/English/parl_cesd_201205_ 03_e_36775.html

3 Stantec Consulting Company. Analysis of contaminants in tissues of fish captured in the Yellowknife Bay area, northwest territories final report. retrieved from public works and government services Canada, 2014.

4 Ratnaike RN. Acute and chronic arsenic toxicity. Postgrad Med J 2003;79:391-6.

5 Hong Y-S, Song K-H, Chung J-Y. Health effects of chronic arsenic exposure. J Prev Med Public Health 2014;47:245-52.

6 Agency for toxic substances and disease registry (ATSDR). Toxicological profile for arsenic. Atlanta, GA, 2007. www.atsdr.cdc. gov/

7 Abernathy CO, Thomas DJ, Calderon RL. Toxicity and risk assessment of trace elements health effects and risk assessment of arsenic 1,2. Available: https://academic.oup.com/jn/article-abstract/ 133/5/1536S/4558544 [Accessed 19 Aug 2019].

8 Kapaj S, Peterson H, Liber K, et al. Human health effects from chronic arsenic poisoning-a review. J Environ Sci Health A Tox Hazard Subst Environ Eng 2006;41:2399-428.

9 Abernathy C, Liu Y-P, Longfellow D, et al. Arsenic: health effects, mechanisms of actions, and research issues. Available: https://ehp. niehs.nih.gov/doi/pdf/10.1289/ehp.99107593 [Accessed 19 Aug 2019].

10 Tchounwou PB, Yedjou CG, Patlolla AK, et al. Heavy metal toxicity and the environment. Exp Suppl 2012;101:133-64.

11 Han WK, Bailly V, Abichandani R, et al. Kidney injury molecule-1 (KIM-1): a novel biomarker for human renal proximal tubule injury. Kidney Int 2002;62:237-44.

12 Cárdenas-González M, Osorio-Yáñez C, Gaspar-Ramírez O, et al. Environmental exposure to arsenic and chromium in children is associated with kidney injury molecule-1. Environ Res 2016;150:653-62.

13 Beamer P, Klimecki W, Loh M, et al. Association of children's urinary CC16 levels with arsenic concentrations in multiple environmental media. Int J Environ Res Public Health 2016;13:521.

14 Ahmed S, Akhtar E, Roy A, et al. Arsenic exposure alters lung function and airway inflammation in children: a cohort study in rural Bangladesh. Environ Int 2017;101:108-16.

15 Health Canada. Second report on human biomonitoring of environmental chemicals in Canada-Results of the Canadian health measures survey cycle 2 (2009-2011). Ottawa, Ontario, 2013. https:// www.healthcanada.gc.ca

16 Agusa T, Fujihara J, Takeshita H, et al. Individual variations in inorganic arsenic metabolism associated with AS3MT genetic polymorphisms. Int J Mol Sci 2011;12:2351-82.

17 Agusa T, Iwata H, Fujihara J, et al. Genetic polymorphisms in glutathione S-transferase (GST) superfamily and arsenic metabolism in residents of the red River delta, Vietnam. Toxicol Appl Pharmacol 2010;242:352-62. 
18 Applebaum KM, Karagas MR, Hunter DJ, et al. Polymorphisms in nucleotide excision repair genes, arsenic exposure, and nonmelanoma skin cancer in New Hampshire. Environ Health Perspect 2007:115:1231-6.

19 Banerjee M, Marensi V, Conseil G, et al. Polymorphic variants of MRP4/ABCC4 differentially modulate the transport of methylated arsenic metabolites and physiological organic anions. Biochem Pharmacol 2016;120:72-82.

20 De Chaudhuri S, Ghosh P, Sarma N, et al. Genetic variants associated with arsenic susceptibility: study of purine nucleoside phosphorylase, arsenic (+3) methyltransferase, and glutathione $S$ transferase omega genes. Environ Health Perspect 2008;116:501-5.

21 Schläwicke Engström K, Broberg K, Concha G, et al. Genetic polymorphisms influencing arsenic metabolism: evidence from Argentina. Environ Health Perspect 2007;115:599-605.

22 Fujihara J, Soejima M, Yasuda T, et al. Global analysis of genetic variation in human arsenic ( +3 oxidation state) methyltransferase (AS3MT). Toxicol Appl Pharmacol 2010;243:292-9.

23 Gomez-Rubio P, Meza-Montenegro MM, Cantu-Soto E, et al. Genetic association between intronic variants in AS3MT and arsenic methylation efficiency is focused on a large linkage disequilibrium cluster in chromosome 10. J App/ Toxicol 2010;30:260-70.

24 Hsu L-I, Wu M-M, Wang Y-H, et al. Association of environmental arsenic exposure, genetic polymorphisms of susceptible genes, and skin cancers in Taiwan. Biomed Res Int 2015;2015:1-10.
25 Lesseur C, Gilbert-Diamond D, Andrew AS, et al. A case-control study of polymorphisms in xenobiotic and arsenic metabolism genes and arsenic-related bladder cancer in New Hampshire. Toxicol Lett 2012;210:100-6.

26 Gabriel S, Ziaugra L, Tabbaa D. SNP genotyping using the sequenom massARRAY iPLEX platform. In: Current protocols in human genetics. Hoboken, NJ: John Wiley \& Sons, Inc, 2009.

27 Health Canada. Forth report on human biomonitoring of environmenta chemicals in Canada - results of the Canadian health mesures survey. Ottawa, Ontario, 2017.

28 Button M, Jenkin GRT, Harrington CF, et al. Human toenails as a biomarker of exposure to elevated environmental arsenic. J Environ Monit 2009;11:610

29 Mandal BK, Ogra Y, Suzuki KT. Speciation of arsenic in human nail and hair from arsenic-affected area by HPLC-inductively coupled argon plasma mass spectrometry. Toxicol Appl Pharmacol 2003;189:73-83.

30 Normandin L, Ayotte P, Levallois P, et al. Biomarkers of arsenic exposure and effects in a Canadian rural population exposed through groundwater consumption. J Expo Sci Environ Epidemiol 2014;24:127-34

31 Pearce DC, Dowling K, Gerson AR, et al. Arsenic microdistribution and speciation in toenail clippings of children living in a historic gold mining area. Sci Total Environ 2010;408:2590-9. 